\title{
Trapping tomato fruitworm in the Central Valley
}

\author{
Michael P. Hoffmann \\ Richard Coviello \\ Donald Rough \\ a Frank G. Zalom \\ Peter B. Goodell
}

\section{Pheromone traps in the San Joaquin and Sacramento valleys indicate that seasonal patterns of the tomato fruitworm are similar across large areas. Catches were greatest late in the season. A non-pest species (false corn earworm), also captured at all locations, is easily confused with the pest.}

The tomato fruitworm (Heliothis zea [Boddie]), also called the corn earworm or bollworm, is a pest of several crops grown in California, including tomatoes, cotton, beans, and sweet corn. The adults are excellent fliers capable of dispersing over wide areas. Larvae generally feed within the fruiting stage of the crops they attack, and their feeding results in reduced yields or crop quality. For example, excessive damage or larvae in harvested loads of processing tomatoes can necessitate the re-sorting of loads or may result in rejection of the harvested crop. Either alternative is costly to thegrower. Because of this, the tomato fruitworm is considered one of the more important pests of processing tomatoes.

An Integrated Pest Management (IPM) program for the lepidopterous pests of processing tomatoes has been developed and implemented in the Sacramento Valley. It includes a technique for sampling fruit and plants for worm damage and eggs of the tomato fruitworm, as well as decision guidelines for appropriate treatment. Observations during the development and field testing of this program and during more recent research indicated that the seasonal activity of the tomato fruitworm may be fairly consistent over large geographic areas. For example, tomato fruitworm males captured in pheromone traps in processing tomato fields as far as 20 miles apart appeared

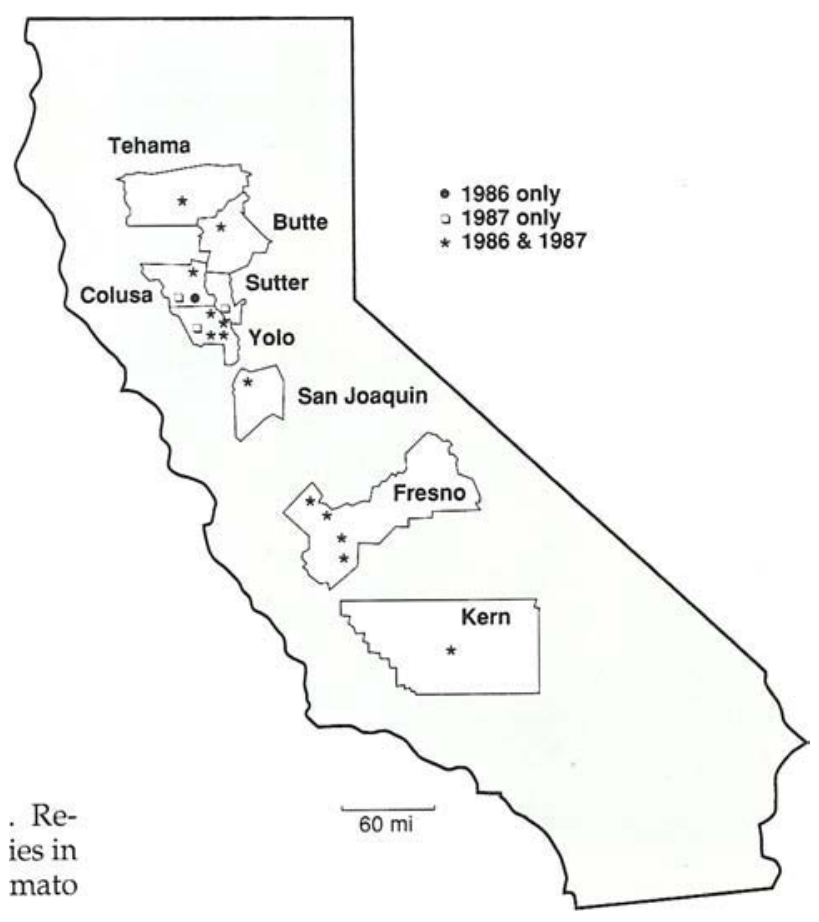

to follow similar seasonal patterns searchers have also observed similarit mato the seasonal oviposition patterns of to fruitworm in California and elsewhere.

Pheromone traps could complement the IPM program for processing tomatoes by helping determine when to begin sampling for fruitworm eggs. Fruitworm egg sampling now begins at 1,300 degree-days $\left({ }^{\circ} \mathrm{D}\right.$, with a lower threshold of $50^{\circ} \mathrm{F}$ ) after planting, regardless of when this occurs during the season. Late-season fields are most likely to incur damage from tomato fruitworm, but we do not know just when these infestations occur. Since pheromone trap catches and fruitworm oviposition in processing tomatoes are correlated from late July to peak oviposition (unpublished data), traps could improve the efficiency of sampling for fruitworm eggs by indicating when moth activity, and thus oviposition, occurs. If the trap-catch patterns were found to be similar over large areas, a few tomato fruitworm traps could be used to help schedule egg sampling for the entire area.

One potential difficulty with traps baited for the tomato fruitworm is the unwanted capture of Heliothis phloxiphaga Grote \& Robinson, sometimes called the false corn earworm. This species is widely distributed in California, feeds primarily on weeds, and is not a pest. Other researchers have demonstrated that the pheromones of these two related insects are somewhat similar, and as a result false corn earworm males are attracted to the tomato fruitworm pheromone and vice versa.

False corn earworm males caught in tomato fruitworm traps could cause confusion and lead to misinterpretation of catch data. The false corn earworm is smaller and generally darker than the tomato fruitworm, but after a few days in a trap, abrasion will have worn away most of its wing scales and distinguishing color patterns. The two species can then be distinguished only by ex-
The authors operated Heliothis zea traps in seven counties in 1986, and eight counties in 1987.

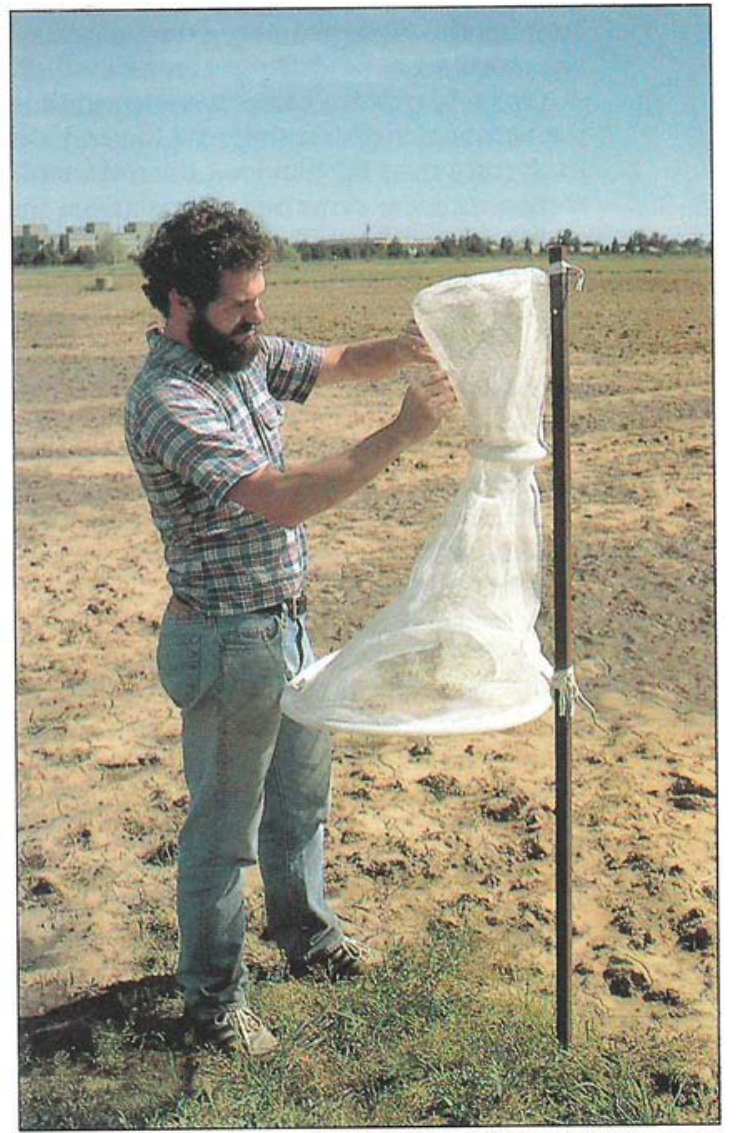

A researcher checks for moths in a tomato fruitworm trap. Friction within the trap can render the wing markings of the tomato fruitworm moth (Heliothis zea) practically indistinguishable from those of the false corn earworm moth ( $H$. phloxiphaga) in the field. 


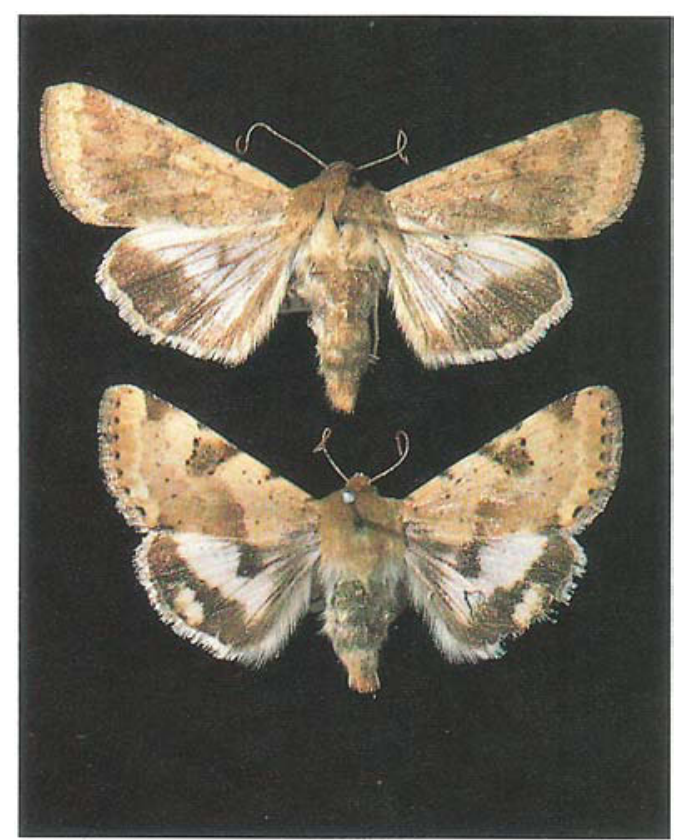

Tomato fruitworm (Heliothis zea, top) is easily confused with false corn earworm $(H$. phloxiphaga, bottom).

amining the male genitalia, a time-consuming process.

Our research objectives were to monitor the seasonal flight activity of the tomato fruitworm over the San Joaquin and Sacramento valleys, determine similarities in seasonal activity over thearea, and determine whether the traps would capture enough $H$. phloxiphaga to affect the accurate interpretation of trap catches.

\section{Methods and materials}

We used Scentry brand Heliothis traps at all locations. Most of the traps were installed in April or May and operated until September orOctober. Traps were emptied at least once a week. At locations away from UC Davis, trap operators placed the captured moths in jars of $75 \%$ ethyl alcohol. These moths were periodically shipped to UC Davis, where they were examined, their species determined, and their numbers recorded.

Rubber septa impregnated with tomato fruitworm pheromone were used in all traps. The septa were treated with a 3.0:0.09 $\mathrm{mg}$ dichloromethane solution of (Z)-11-hexadecenal and (Z)-9-hexadecenal at the Yakima, Washington USDA-ARS laboratory of Les McDonough, and shipped to us. Septa were stored at $15^{\circ} \mathrm{F}$ until use. Following the recommendations from earlier field longevity tests (California Agriculture, September-October 1986), we replaced septa monthly.

Fifteen and seventeen traps were successfully operated in 1986 and 1987, respectively, in eight counties: Tehama (Red Bluff), Butte (Chico), Colusa (Princeton,
Arbuckle, College City), Sutter (Robbins), Yolo (northeast \& east county, Woodland, UCDavis), San Joaquin (King Island), Fresno (Firebaugh, Mendota, UC West Side Field Station, Huron), and Kern (Arvin) (fig. 1). The two traps operated at UC Davis were designated "N. UCD" (north) and "S. UCD" (south).

The north-south range of this trapping program covered approximately 340 miles. The traps were located next to processing tomato fields, except in Tehama, Butte, and San Joaquin counties, where traps were located next to sugarbeets or beans. In all cases, other crops were also in the immediate vicinity of traps, and the agricultural and nonagricultural habitats surrounding the traps were diverse, varying considerably among locations. Cotton and tomatoes dominated the cropping around the southern traps, while traps to the north were in a mix of several crops, including rice, processing tomatoes, and tree crops.

\section{Results and discussion}

To determine similarities in the seasonal activity of the tomato fruitworm at different locations, we identified and compared the dates of four trapping events. These events included first catch, first peak of the season, initiation of late-season peak, and late peak.

The "first catch" was defined as the first of three successive observations with catches

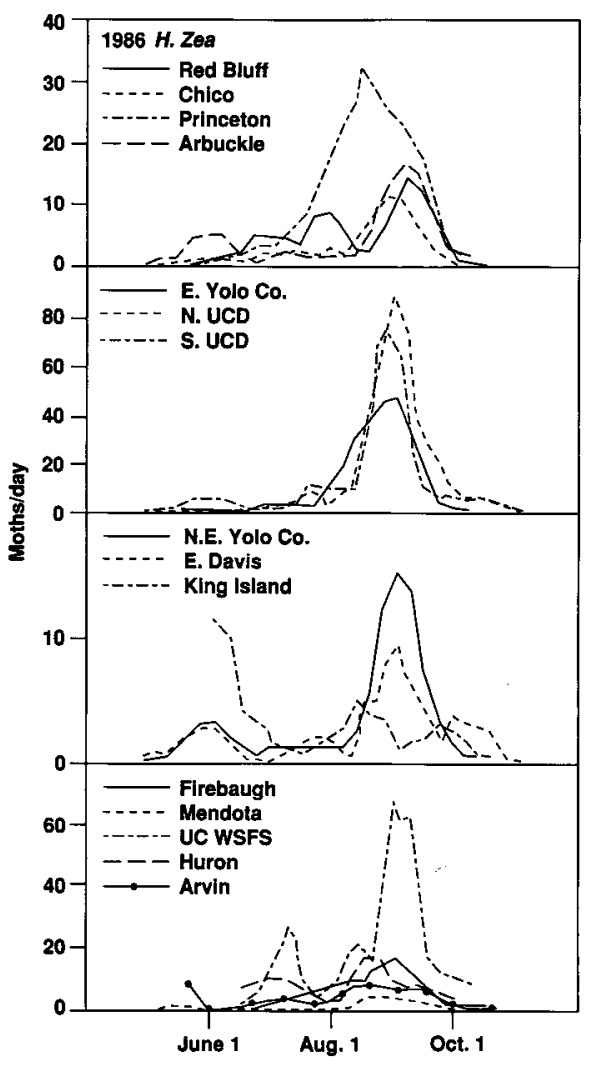

greater than zero. The first catch generally occurred in the first week of May each year (figs.2and3). Only traps that werefunctional early enough in the season to have initial catches of zero were used to tabulate first catch. Since not all traps were operational early enough in the season, and not all trap catch patterns met the criteria, we registered only seven first catches, six of them in 1986. After first catch, a "first peak" was observed around May 31 in 1986 and May 16 in 1987. Early season data on fruitworm activity in the central San Joaquin Valley is limited to the UCWestSideField Station atFive Points. A few of the San Joaquin Valley traps were operated for only a short time, and few fruitworms were caughtin those traps. These locations did not contribute greatly to our study.

The period of greatest activity for tomato fruitworm came in August and September for much of California (figs. 2 and 3). This late-season flight typically started in late July or early August and was followed by a high peak in trap catch around September 1. We defined the "late peak" as the date of the largest trap catch after August 1. We defined "initiation of late-season peak" as either the day of lowest trap catch immediately before the late peak, or the first of two consecutive observations just before the late peak for which the rate of catch increased by more than one moth perday. Weused unsmoothed

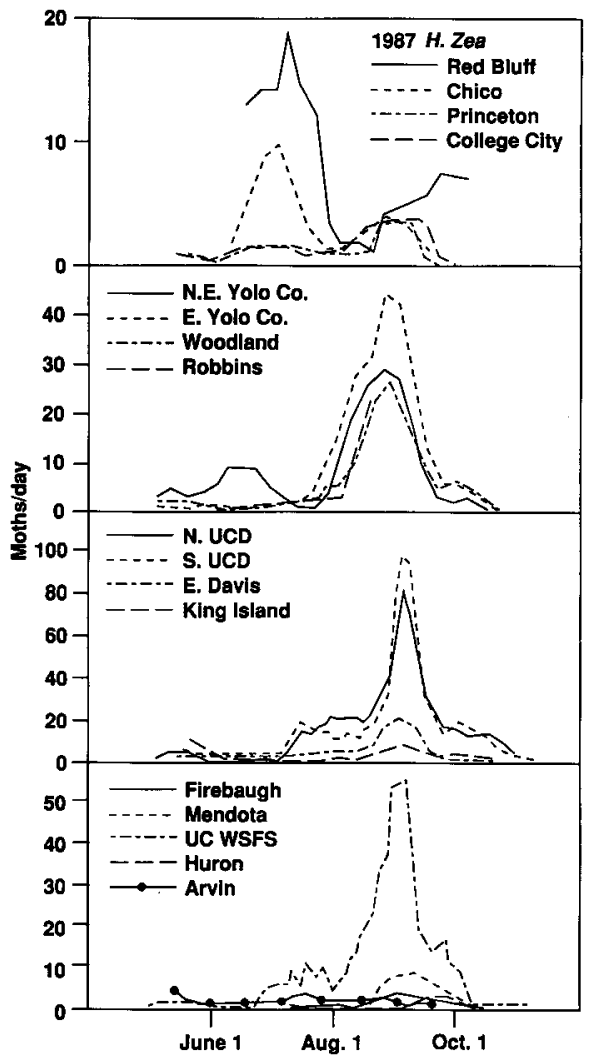

Fig. 2. Seasonal pheromone trap catch patterns of male Heliothis zea in 1986 and 1987. 
data to identify dates of first catch. All other dates were based on data smoothed by a three-observation running mean.

The late-season trapactivity reported here corresponds to the time of year (mid-August or later) when the potential for fruitworm damage to processing tomatoes is greatest in the Sacramento Valley. Most processing tomatoes in the San Joaquin Valley are harvested before this time, so they generally escape fruitworm damage.

We analyzed the data to determine whether there was a correlation between the dates of the four trapping events at each location and latitude of observation (measured in miles north of Arvin). In neither year were the correlations found to be significant $(P>0.05)$, so there was no consistent shift from south to north in the timing of the trapping events. In addition, the variability about the mean dates for these events was relatively small (table 1 ). Trapping events that did not clearly fit the criteria of the four specified events were not included in our analyses. Together, the general absence of a latitude-related trend in the timing of trapping events and the small confidence interval about the mean dates of the events indicate that the tomato fruitworm's seasonality is similar for large areas of California (figs. 2 and 3).

A generation of $H$. zea takes $968^{\circ} \mathrm{D}$ using lower and upper thresholds of $57^{\circ}$ and $94^{\circ} \mathrm{F}$ (see California Agriculture, January-February 1983). Although we were unable to associate degree-day requirements per generation with peaks in trap catch, the degree-day information helped us identify the number of generations possible each year. From the beginning of trapping activity in early May through October, on average $2,553.7^{\circ} \mathrm{D}$ and $2,768.7^{\circ} \mathrm{D}$ accumulated across all locations in 1986 and 1987, respectively. This is enough degree days to complete two full generations and part of a third. At the more southerly locations, the warmer temperatures generated enough degree days to permit three full generations and a partial fourth. However, data on early season trapping activity (first catch, first peak) werelimited to the UCWestSide Field Station, so determing the starting point for degree-day accumulation at these southern locations was difficult.

Other researchers have reported that pheromone trap catches increase during a full moon. We could not associate any changes in trap catch data with moon phase,

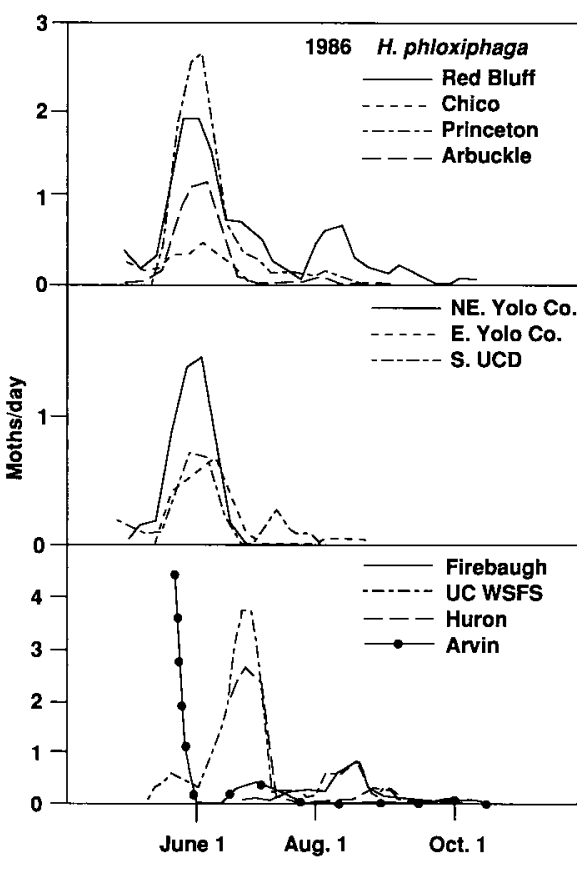

Fig. 3. Seasonal pheromone trap catch patterns of male Heliothis phloxiphaga in 1986.

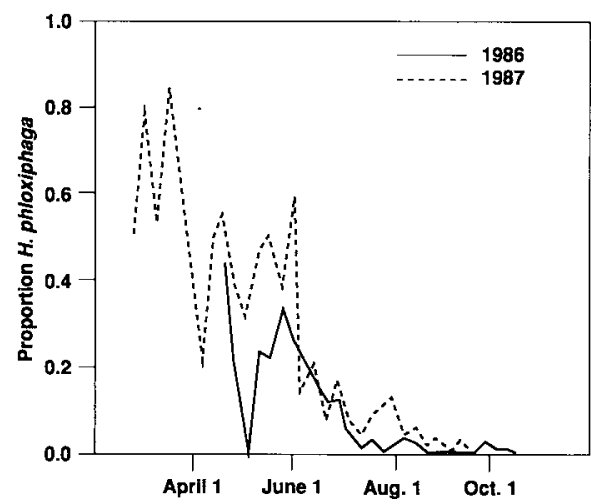

Fig. 4. Heliothis phloxiphaga moths captured in pheromone traps, expressed as a proportion of all moths caught.

but our observations may have been too infrequent for us to detect the influence of moon phase.

Although the number of $H$. phloxiphaga males captured was low, they were captured at all trap locations in both years. Catches for 1986 (fig. 4) are representative of both years' observations. Most $H$. phloxiphaga were captured in May and June, not when

TABLE 1. Mean day-of-year and confidence intervals about the mean $(P>0.05)$ for four trapping events recorded in the San Joaquin and Sacramento valleys in 1986 and 1987

\begin{tabular}{llllllllll}
\hline \hline & \multicolumn{7}{c}{ Mean day of year (confidence interval in parentheses) } \\
\cline { 2 - 9 } Year & First catch & $\mathbf{n}$ & First peak & $\mathbf{n}$ & $\begin{array}{c}\text { Start of } \\
\text { late peak }\end{array}$ & $\mathbf{n}$ & Late peak & $\mathbf{n}$ \\
\hline 1986 & $128.2(9.1)$ & 6 & $150.8(4.9)$ & 9 & $212.2(6.6)$ & 14 & $241.4(4.2)$ & 15 \\
1987 & $126.0(-)$ & 1 & $136.0(8.8)$ & 5 & $217.6(6.0)$ & 14 & $243.6(4.7)$ & 15 \\
\hline
\end{tabular}

fruitworm catches were greatest. In 1987 a single trap operated at Davis starting January 5 showed that $H$. phloxiphaga was present as early as February. From this early date, trap catches gradually increased until early May. In general, there were few distinct peaks in trap catch of $H$. phloxiphaga after May and June.

The potential for confusion of the two species appears greatest early in the season, when $H$. phloxiphaga accounts for a large proportion of the moths caught. If early season catches of tomato fruitworm were ultimately used as a reference point for predictive purposes, confusion between species at this time of year could limit the commercial usefulness of traps.

\section{Conclusion}

Because the tomato fruitworm is highly mobile and feeds mainly on host plants, the interpretation and prediction of its seasonal activity is difficult. In addition, environmental conditions such as temperature and wind can influence the response and capture of male fruitworm in traps. Considering these complicating factors, it is encouraging to note that seasonal activity was relatively similar over large areas observed in this trapping program. Because of regional similarities in the pest's seasonal activity, installing a few traps could help identify the timing of flights for areas such as counties. This information would be useful to growers practicing IPM on processing tomatoes, and could also be important for managing this pest in other crops.

Michael Hoffmann, formerly Staff Research Associate, Department of Entomology, UC Davis, is now Assistant Professor, Department of Entomology, Cornell University; Lloyd T. Wilson is Professor and Entomologist, Department of Entomology, Texas A E M University; Frank G. Zalom is Director, IPM Implementation Group, UCDavis; Richard Covielloand Michael Murray are Farm Advisors in Fresno and Colusa counties, respectively; Peter B. Goodell is Area IPM Advisor, southern San Joaquin Valley; and Donald Rough is Farm Advisor (Emeritus), San Joaquin County.

The authors acknowledge the assistance of Joel Kitzmiller, Bob Hanke, Neil Phillips, Matt Falk, and Brad Bell, who operated additional traps, and Richard Hilton, Dennis Jones, Louis Hesler, and Jeff Routh, who examined and recorded trap catches. We thank Les McDonough, USDA-ARS, Yakima, Washington for providing tomato fruitworm pheromonelures, and Tom Eichlin, California Department of Food and Agriculture, for confirming our identification of Heliothis phloxiphaga. This research was supported in part by the IPM Implementation Group. Photographs are by Jack Kelly Clark, Visual Media, Cooperative Extension, UC Davis. (smoothed with three-observation running mean). 